\title{
The PHF6 Mutation c.1A>G; pM1V Causes Börjeson-Forsman-Lehmann Syndrome in a Family with Four Affected Young Boys
}

\author{
Anja Ernst $^{a}$ Vang Q. Le ${ }^{a}$ Allan T. Højland ${ }^{b}$ Inge S. Pedersen ${ }^{a}$ \\ Tine H. Sørensen ${ }^{c}$ Lise L. Bjerregaard ${ }^{c}$ Troels J.B. Lyngbye ${ }^{e, f}$ \\ Ninna M. Gammelager ${ }^{b}$ Henrik Krarup ${ }^{a}$ Michael B. Petersen ${ }^{b}$ d \\ a Section of Molecular Diagnostics, Clinical Biochemistry, and Departments of ${ }^{b}$ Clinical Genetics and c Pediatrics, \\ Aalborg University Hospital, ${ }^{d}$ Department of Clinical Medicine, Aalborg University, and ${ }^{e}$ Center for Deafblindness \\ and Hearing Impairment, Aalborg, and fDepartment of Pediatrics, Aarhus University Hospital, Aarhus, Denmark
}

\author{
Key Words \\ Börjeson-Forsman-Lehmann syndrome · Intellectual \\ disability - Mental retardation P PHF6 - Whole-exome \\ sequencing $\cdot X$-linked inheritance
}

\begin{abstract}
The family presented with 4 boys, 2 sets of brothers, with unexplained intellectual disability. Numerous analyses had been conducted over more than a decade, without reaching a final clinical or molecular diagnosis. According to the pedigree, an X-linked inheritance pattern was strongly suspected. Whole-exome sequencing (WES) with targeted analysis of the coding regions of the $X$ chromosome was carried out in the 4 boys, their mothers, and their shared grandmother. A filtering process searching for nonsynonymous variants and variants in the exon-intron boundaries revealed one variant, c.1A>G; pM1V, in the first codon of the PHF6 gene. The variant was hemizygous in the 4 boys and heterozygous in the 2 mothers and the grandmother. Mutations in the PHF6 gene are known to cause Börjeson-Forsman-Lehmann syndrome (BFLS). The boys were reexamined after the finding of the mutation, and the phenotype fitted perfectly with
\end{abstract}

(c) 2015 S. Karger AG, Basel

$1661-8769 / 15 / 0064-0181 \$ 39.50 / 0$
BFLS. The mutation found in the PHF6 gene is causative for the intellectual disability in this family. We also conclude that WES of the $X$ chromosome is a powerful tool in families where an X-linked inheritance pattern is suspected.

(c) 2015 S. Karger AG, Basel

The mental retardation syndrome Börjeson-ForsmanLehmann syndrome (BFLS) was described for the first time in 1962 in 3 related young men [Borjeson et al., 1962]. The inheritance pattern was expected to be Xlinked recessive, which was supported in the following decades [Ardinger et al., 1984; Carter et al., 2009]. The clinical phenotype of the males with this syndrome is variable, and is characterized by severe intellectual disability, hypogonadism, hypotonia, poor feeding, truncal obesity, gynecomastia, big ears with fleshy lobes, broad feet with short toes, tapered fingers, and coarsening of facial features [Turner et al., 2004; Gécz et al., 2006; Carter et al., 2009]. Female carriers are usually not affected due to X-chromosome inactivation, but might be mildly affected due to skewed X-chromosome inactivation [Crawford et al., 2006; Zweier et al., 2013]. In 1989, the

\section{KARGER 125}

E-Mail karger@karger.com www.karger.com/msy 
Table 1. Clinical features of the 4 boys

\begin{tabular}{|c|c|c|c|c|}
\hline & \multicolumn{4}{|l|}{ Patients } \\
\hline Pregnancy & normal & normal & $\begin{array}{l}\text { maternal gestational } \\
\text { diabetes }\end{array}$ & $\begin{array}{l}\text { maternal gestational } \\
\text { diabetes }\end{array}$ \\
\hline Delivery & normal & caesarean & caesarean & caesarean \\
\hline External genitalia & normal & normal & normal & normal \\
\hline Neonatal tonus & hypertonic LE and UE & hypertonic LE, hypotonic UE & hypertonic & hypertonic \\
\hline Current tonus & hypotonic & hypotonic & hypotonic & hypotonic \\
\hline Motor milestones & delayed & delayed & delayed & delayed \\
\hline Spoken language & no & no & no & no \\
\hline Short toes & NR & NR & NR & NR \\
\hline Tapered fingers & NR & NR & NR & NR \\
\hline Gynecomastia & NR & NR & NR & NR \\
\hline Truncal obesity & NR & NR & NR & NR \\
\hline Coarsening of facial features & reported & reported & reported & reported \\
\hline Micro- or macrocephaly & no & no & NR & NR \\
\hline Seizures & yes & no & no & no \\
\hline Short stature & low normal & low normal & NR & NR \\
\hline Other features & $\begin{array}{l}\text { umbilical hernia, hoarse } \\
\text { voice, retinopathy }\end{array}$ & $\begin{array}{l}\text { heart defect, kidney anomaly, } \\
\text { 1p21.1 deletion }\end{array}$ & hypermetropia & $\begin{array}{l}\text { hypermetropia, } \\
\text { unilateral hearing loss }\end{array}$ \\
\hline
\end{tabular}

$\mathrm{LE}=$ Lower extremity; $\mathrm{NR}=$ not reported; $\mathrm{UE}=$ upper extremity.

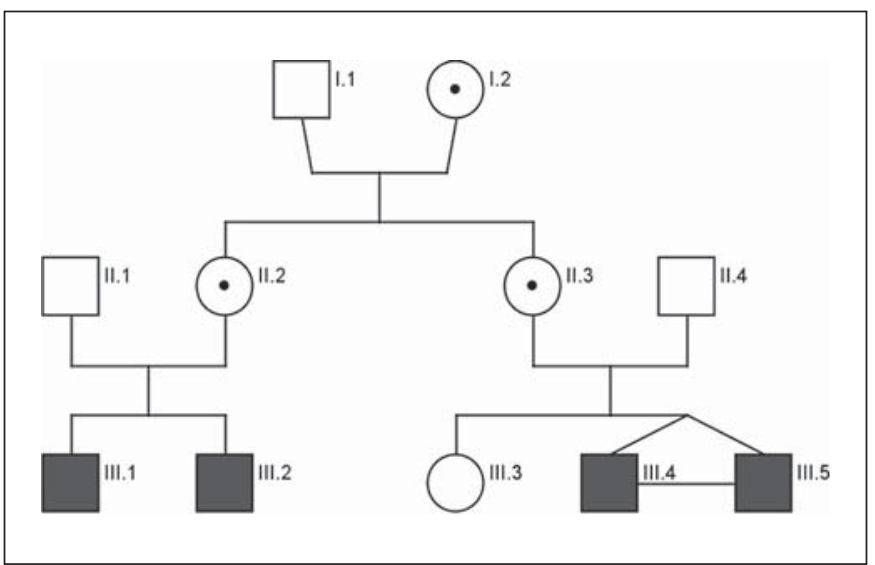

Fig. 1. The family pedigree with the 4 affected boys, III.1, III.2, III.4 and III.5, depicted as solid black squares. The healthy carrier mothers, II.2 and II.3, and their shared grandmother, I.2, are circles with a dot. syndrome was linked to Xq26q27, and in 2002 the associated gene was found to be the PHD-finger gene 6 (PHF6) [Mathews et al., 1989; Turner et al., 1989; Lower et al., 2002]. PHF6 is highly conserved in vertebrates, but the cellular function of PHF6 is not known [Lower et al., 2002; Voss et al., 2007]. The protein has 4 nucleolization signals [Voss et al., 2007] and is believed to be involved in transcription and/or in nucleosome assembly [Todd and Picketts, 2012]. To date, at least 17 families with 41 affected males have been described with mutations in PHF6 [Zweier et al., 2013].

\section{Materials and Methods}

The family counseled was a Danish family with 4 boys, 3-12 years of age, with developmental delay (the pedigree is shown in fig. 1). All 4 had intellectual disability, coarsening of facial features, hypotonia, delayed motor milestones, and no spoken language (table 1). Prior to the diagnosis, none of the boys were described as having hypogonadism, broad feet with short toes or tapered fin- 
Table 2. Variants after filtering

\begin{tabular}{lllrll}
\hline Variant & Gene & Classification & Exon & HGVS coding & HGVS protein \\
\hline X:123034511-SNV & XIAP & nonsynonymous SNV & 6 & c.1268A $>$ C & p.Gln423Pro \\
X:123554646-SNV & ODZ1 & synonymous & 25 & c.4497A $>$ G & p. $=$ \\
X:130678596-SNV & OR13H1 & synonymous & 1 & c.549C $>$ G & p. $=$ \\
X:133511648-SNV & PHF6 & initiating codon & 2 & c.1A $>$ G & p.Met1Val
\end{tabular}

Variants according to the Genome Reference Consortium (GRCh37). HGVS = Human Genome Variation Society.

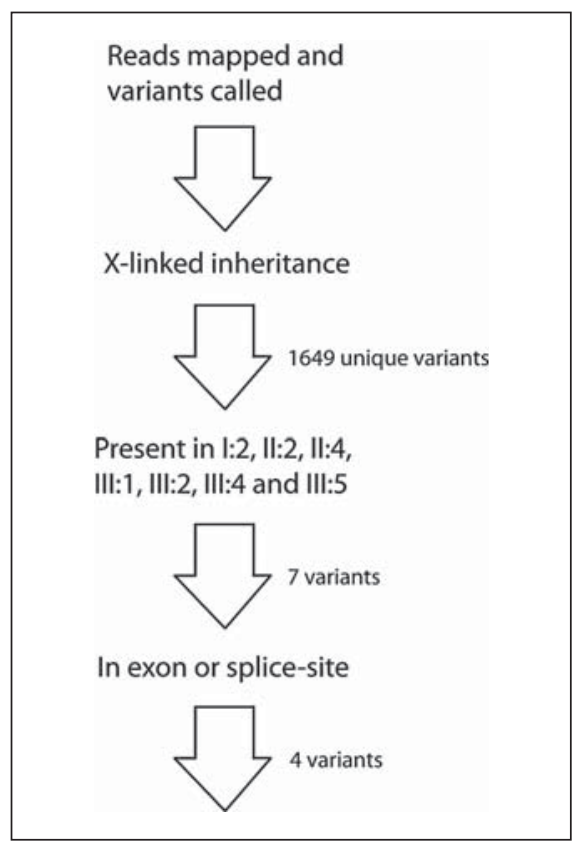

Fig. 2. Filtering of variants. After filtering, 7 variants were found to be present in all family members. Four of them were splice-site or exonic variants. Two of these 4 were synonymous, leaving only 2 potentially disease causing variants in the XIAP and PHF6 genes, respectively.

gers in the pediatric and genetic files. All 4 were tested by array CGH. In III:2, a $2.5-\mathrm{Mb}$ deletion of $1 \mathrm{p} 21.1$ was detected and thought to be the cause of his symptoms. However, the 4 boys had a similar phenotype, and in the other 3 boys this deletion was not detected. III: 1 was also tested for metabolic diseases and fragile $\mathrm{X}$ syndrome. III:1 and III:2 were karyotyped. III:4 and III:5 were tested for mitochondrial diseases by muscle biopsy. Based on the pedigree and the similar phenotype, X-linked inheritance was strongly suspected.

\section{Whole-Exome Sequencing}

Sequencing of the coding regions and the exon/intron boundaries of the $\mathrm{X}$ chromosome was carried out using whole-exome sequencing (WES). WES was performed in the 4 affected boys III:1, III:2 , III:4, and III:5; their respective mothers II:2 and II:3, and their maternal grandmother I:2. In brief, $3 \mu \mathrm{g}$ of DNA was fragmented through acoustic sonication on a Covaris ${ }^{\circledR}$ S2 system and enriched using Agilent SureSelect Whole Exome Capture kit prior to $75 \mathrm{bp}$ forward sequencing on SOLiD Wildfire 5500xl (Life Technologies).

\section{Library Preparation and Sequencing}

$3 \mu \mathrm{g}$ of DNA was fragmented through acoustic sonication on a Covaris ${ }^{\circledR}$ S2 system according to the Fragment Library Preparation Using the AB Library Builder ${ }^{\mathrm{TM}}$ system 5500 Series Solid $^{\mathrm{TM}}$ Systems User Guide.

The fragmented DNA was then used for Fragment Library Preparation Using the AB Library Builder ${ }^{\mathrm{TM}}$ System adding $1.7 \mu \mathrm{l}$ of adaptor P1 and barcoded adaptors followed by nick translation and 6 cycles of amplifications according to the protocol.

The libraries were quantified using SOLiD ${ }^{\mathrm{TM}}$ Library TaqMan Quantitation Kit. The 7 barcoded libraries were pooled in equal amounts in 2 tubes, one with 4 barcoded libraries (125 ng of each) and one with 3 barcoded libraries (167 ng of each). To each tube of pooled libraries, $5 \mu \mathrm{l}$ human Cot-1 DNA $(0.1 \mathrm{mg} / \mathrm{ml})$, $5 \mu \mathrm{l} 1$ blocker (ABI) and $5 \mu \mathrm{l}$ barcode $1-16$ blocker (ABI) were added. The mix was dried down in a Savant Speed Vac (ThermoScietific) at medium drying rate, and hereafter resuspended in $9 \mu \mathrm{H} \mathrm{H}_{2} \mathrm{O}$, ready for use with the SureSelect ${ }^{\mathrm{XT}}$ Target Enrichment System for Solid 5500 Multiplexing Sequencing v1. The $9 \mu \mathrm{l}$ library pool was denatured at $95^{\circ} \mathrm{C}$ for $5 \mathrm{~min}$ followed by the addition of SureSelect hybridization buffer (13 $\mu \mathrm{l})$, RNase block ( $2 \mu \mathrm{l} 25 \%$ dil.) and $5 \mu \mathrm{l}$ SureSelect capture library (Agilent SureSelect Whole Exome Capture kit V5). The solution was incubated for $24 \mathrm{~h}$ at $65^{\circ} \mathrm{C}$.

The captured library was collected by binding to Dynabeads MyOne Streptavidine T1 and washing of beads was carried out according to the SureSelect protocol.

The $30 \mu$ post-capture beads with DNA library was then converted to a 5500 wildfire library using 10 cycles of amplification according to the Conversion of 5500 Library to 5500 W Library protocol.

$4 \mathrm{nM}$ of the pool of 7 barcoded libraries were sequenced with 50 bp forward sequencing on the SOLiD W 5500xl (Life Technologies) resulting in between 77 and 167 million raw reads for each library. 

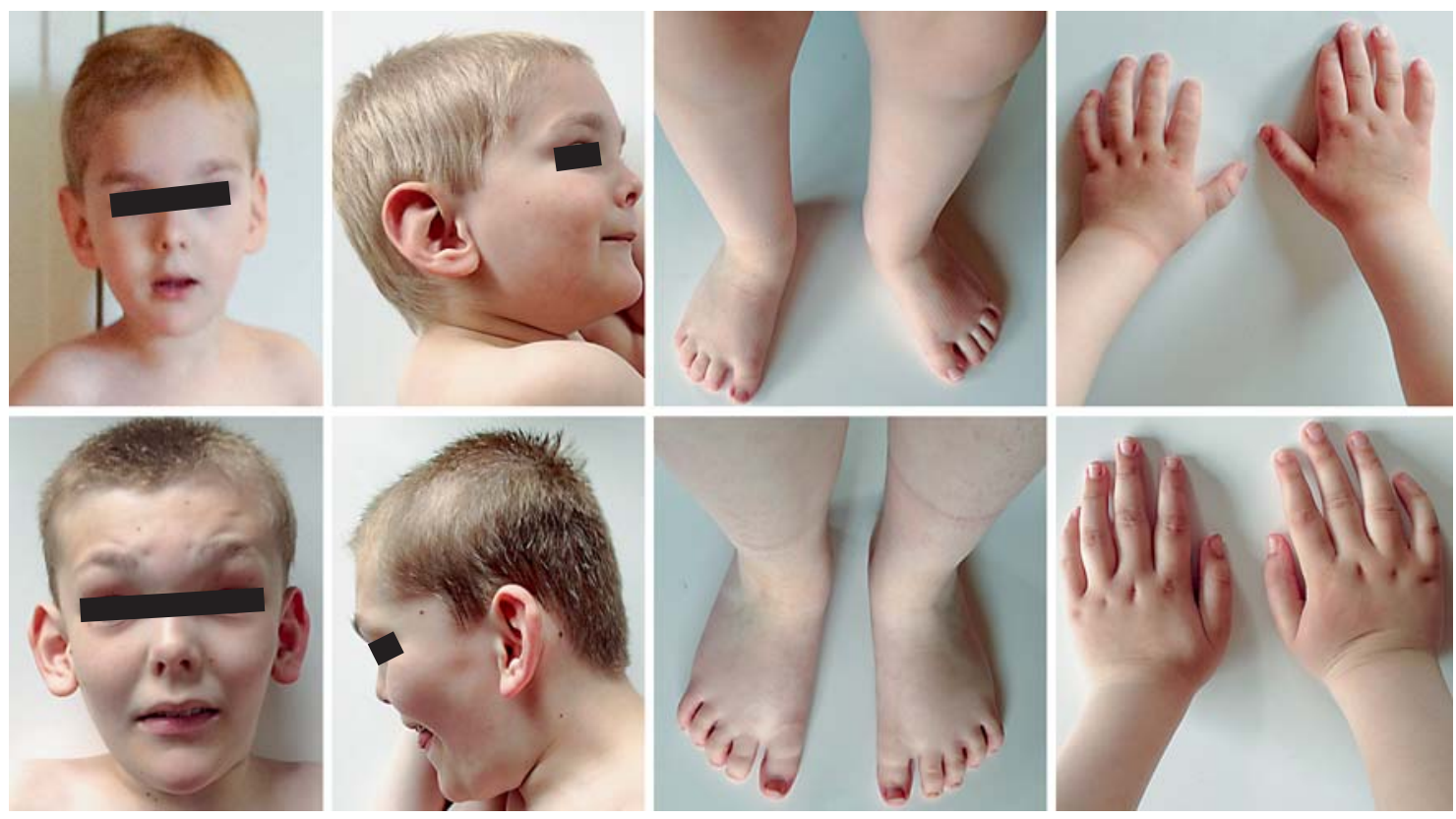

Fig. 3. Photos showing the clinical features of the 2 brothers III.1 and III.2. The facial photos show the enlarged ears with fleshy lobes. The hands show tapering of the finger, and the feet are broad with short toes.

\section{Data Analyses and Results}

The raw reads in the XSQ files were first joined by an in-house program into one XSQ file. The joining step allows LifeScope (Life Technologies) to produce one BAM file for each sample. The joined XSQ file was then run in LifeScope Software 2.5 (Life Technologies) by using the Whole Exome Fragment Resequencing workflow. In brief, the workflow contains color space error correction, filtering of short- and low-quality reads, sequence alignment, calculate statistics of the aligned reads, and variant calling.

LifeScope could identify a total of 86,926 variants for all 7 subjects. Tertiary data analysis on variants was done with SNP \& Variation Suite (Golden Helix Inc.). Before we performed further data analysis, all variants outside of the $\mathrm{X}$ chromosome were filtered out, leaving a total of 1,649 variants (fig. 2). After filtering variants by genotypes, 7 variants were kept. By coding and noncoding classification, 3 variants were excluded.

Of the 4 remaining variants, the 2 nonsynonymous variants were the most likely candidates to be the cause of the phenotype in the 4 boys (table 2). A missense variant was found in the XIAP gene. Pathogenic mutations in the XIAP gene cause $\mathrm{X}$-linked lymphoproliferative syndrome, which is not consistent with the observed phenotype in the 4 boys.
The second nonsynonymous variant was in the PHF6 gene where pathogenic mutations are known to cause BFLS. The c.1A $>\mathrm{G}$ is a nonsynonymous missense variant in the first codon of the PHF6 gene. There is no downstream alternative start codon, and we therefore expect complete lack of protein production. A different mutation affecting the first amino acid in the PHF6 gene has been reported twice previously as the causal variant in a BFSL family [Lower et al., 2002; Crawford et al., 2006]. The variant was confirmed by Sanger Sequencing.

\section{Discussion}

After the diagnosis of BFLS, the 4 boys were reexamined. All 4 had a weak suck at infancy, hypotonia, developmental delay, no language, hypogonadism, tapered fingers, big ears with fleshy lobes, broad feet with short toes, and a wide gap between the first and second toe (fig. 3). Due to the young age of the 4 affected boys, none of them have developed gynecomastia or truncal obesity yet. The oldest affected boy and his younger brother have no spoken language, but have reasonable perceptive abilities and a continuously developing sign language. Reports from other patients with BFLS also describe a very small vocabulary of only a few words but an ability to use sign language [Zweier et al., 2013]. 


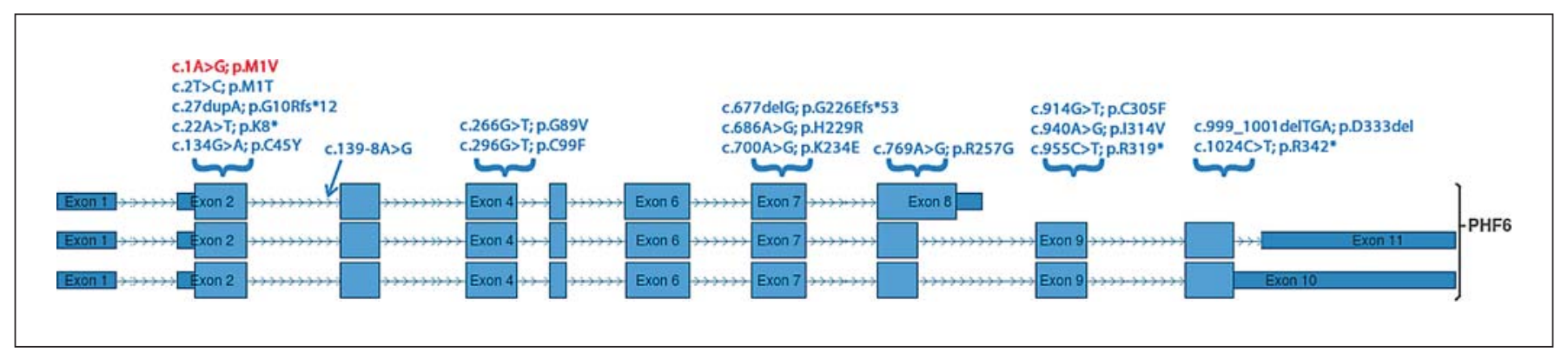

Fig. 4. Reported pathogenic variants in the PHF6 gene. Schematic view of the different mutations described in the PHF6 gene giving rise to BFLS. The mutation found in this family is printed in red [Lower et al., 2002, 2004; Baumstark et al., 2003; Turner et al., 2004; Vallée et al., 2004; Visootsak et al., 2004; Crawford et al., 2006; Carter et al., 2009; Chao et al., 2010; Berland et al., 2011; Zweier et al., 2013].

It has taken 12 years with several counseling sessions and numerous analyses to finally reach a diagnosis for this family. A syndrome being responsible for the phenotype in the oldest boy was suspected before his first birthday. Diagnosing intellectual disability often proves to be difficult due to the heterogeneity of the disease. Intellectual disability shows a variable clinical presentation, and often mutations in different genes give rise to the same or a similar phenotype. This complicates both the clinical diagnosis as well as the genetic diagnosis.

WES has shown it is worth reaching a diagnosis in families where an extensive diagnostic effort such as SNP arrays and targeted sequencing has failed. The benefit of WES is that it covers the entire coding region which is most likely to contain the disease causing variant. WES gives the opportunity to consider large gene panels as well as looking beyond known susceptibility genes and pathways [de Ligt et al., 2012]. However, in our experience WES also has challenges, such as not covering all areas of the exome because of uneven coverage due to the nature of the sequence or capture/amplification of the sequence, which may result in areas not covered at all. Another challenge is heterozygous variants being missed during data analysis if the frequency of the variant is well below $50 \%$.

A Finnish study examined the $\mathrm{X}$ chromosome by WES approach in 14 families suspected of X-linked intellectual disability, and in 6 of the 14 families, genetic and clinical diagnoses was found [Philips et al., 2014]. In the 8 unresolved cases, 5 could also be explained by autosomal recessive inheritance, since only brothers from one set of parents were affected. Our study shows that analysis of the $\mathrm{X}$ chromosome by WES is suitable for families suspected of having X-linked intellectual disability. Especial- ly, if there are boys affected in several branches of the family, reducing the possibility of a rare autosomal recessive variant being the cause of disease.

\section{Conclusion}

A novel mutation c.1A>G; p.M1V in the PHF6 gene was found hemizygous in all 4 boys (III:1, III:2, III:4, and III:5) and heterozygous in the 2 mothers (II:2 and II:3) and the grandmother (I:2). The mutation alters the start codon, where a p.M1T mutation has been previously reported. The mutation caused BFLS in the 4 affected boys with 3 unaffected female carriers. The genotype status of the unaffected sister III.3 is unknown. Several other variants, including nonsense, frameshifts, missense and splice site mutations in the PHF6 gene have been shown to cause BFLS (listed in fig. 4) [Lower et al., 2002, 2004; Baumstark et al., 2003; Turner et al., 2004; Vallée et al., 2004; Visootsak et al., 2004; Crawford et al., 2006; Carter et al., 2009; Chao et al., 2010; Berland et al., 2011; Zweier et al., 2013].

We conclude that sequencing of the X chromosome by WES in families with boys having suspected X-linked intellectual disability is a good choice with a reasonable probability of finding the disease-causing mutation.

\section{Acknowledgment}

The authors would like to thank the families described in this publication for their participation. 


\section{Statement of Ethics}

The parents of the underaged participants have given written consent for WES analysis and for the publication of the results.

\section{Disclosure Statement}

The authors have no conflict of interest to declare.

\section{References}

Ardinger HH, Hanson JW, Zellweger HU: Börjeson-Forssman-Lehmann syndrome: further delineation in five cases. Am J Med Genet 19: 653-664 (1984).

Baumstark A, Lower KM, Sinkus A, Andriuskeviciute I, Jurkeniene L, et al: Novel PHF6 mutation p.D333del causes Börjeson-ForssmanLehmann syndrome. J Med Genet 40:e50 (2003).

Berland S, Alme K, Brendehaug A, Houge G, Hovland R: PHF6 Deletions May Cause Borjeson-Forssman-Lehmann Syndrome in Females. Mol Syndromol 1:294-300 (2011).

Borjeson M, Forssman H, Lehmann O: An Xlinked, recessively inherited syndrome characterized by grave mental deficiency, epilepsy, and endocrine disorder. Acta Med Scand 171: 13-21 (1962).

Carter MT, Picketts DJ, Hunter AG, Graham GE: Further clinical delineation of the BörjesonForssman-Lehmann syndrome in patients with PHF6 mutations. Am J Med Genet A 149A:246-250 (2009).

Chao MM, Todd MA, Kontny U, Neas K, Sullivan MJ, et al: T-cell acute lymphoblastic leukemia in association with Börjeson-ForssmanLehmann syndrome due to a mutation in PHF6. Pediatr Blood Cancer 55:722-724 (2010).

-Crawford J, Lower KM, Hennekam RCM, Van Esch H, Mégarbané A, et al: Mutation screening in Borjeson-Forssman-Lehmann syndrome: identification of a novel de novo PHF6 mutation in a female patient. J Med Genet 43: 238-243 (2006). de Ligt J, Willemsen MH, van Bon BWM, Kleefstra T, Yntema HG, et al: Diagnostic exome sequencing in persons with severe intellectual disability. N Engl J Med 367:1921-1929 (2012).

Gécz J, Turner G, Nelson J, Partington M: The Börjeson-Forssman-Lehman syndrome (BFLS, MIM \#301900). Eur J Hum Genet 14: 1233-1237 (2006).

Lower KM, Turner G, Kerr BA, Mathews KD, Shaw MA, et al: Mutations in PHF6 are associated with Börjeson-Forssman-Lehmann syndrome. Nat Genet 32:661-665 (2002).

Lower KM, Solders G, Bondeson ML, Nelson J, Brun A, et al: $1024 \mathrm{C}>\mathrm{T}(\mathrm{R} 342 \mathrm{X})$ is a recurrent PHF6 mutation also found in the original Börjeson-Forssman-Lehmann syndrome family. Eur J Hum Genet 12:787-789 (2004).

Mathews KD, Ardinger HH, Nishimura DY, Buetow KH, Murray JC, Bartley JA: Linkage localization of Börjeson-Forssman-Lehmann syndrome. Am J Med Genet 34:470-474 (1989).

Philips AK, Sirén A, Avela K, Somer M, Peippo M, et al: X-exome sequencing in Finnish families with intellectual disability - four novel mutations and two novel syndromic phenotypes. Orphanet J Rare Dis 9:49 (2014).

Todd MAM, Picketts DJ: PHF6 interacts with the nucleosome remodeling and deacetylation (NuRD) complex. J Proteome Res 11:43264337 (2012).
Turner G, Gedeon A, Mulley J, Sutherland G, Rae $J$, et al: Börjeson-Forssman-Lehmann syndrome: clinical manifestations and gene localization to Xq26-27. Am J Med Genet 34:463469 (1989).

Turner G, Lower KM, White SM, Delatycki M, Lampe AK, et al: The clinical picture of the Börjeson-Forssman-Lehmann syndrome in males and heterozygous females with PHF6 mutations. Clin Genet 65:226-232 (2004).

Vallée D, Chevrier E, Graham GE, Lazzaro MA, Lavigne PA, et al: A novel PHF6 mutation results in enhanced exon skipping and mild Börjeson-Forssman-Lehmann syndrome. J Med Genet 41:778-783 (2004).

Visootsak J, Rosner B, Dykens E, Schwartz C, Hahn K, et al: Clinical and behavioral features of patients with Borjeson-Forssman-Lehmann syndrome with mutations in PHF6. J Pediatr 145:819-825 (2004).

Voss AK, Gamble R, Collin C, Shoubridge C, Corbett $M$, et al: Protein and gene expression analysis of $P h f 6$, the gene mutated in the Börjeson-Forssman-Lehmann Syndrome of intellectual disability and obesity. Gene Expr Patterns 7:858-871 (2007).

Zweier C, Kraus C, Brueton L, Cole T, Degenhardt $\mathrm{F}$, et al: A new face of Borjeson-Forssman-Lehmann syndrome? De novo mutations in PHF6 in seven females with a distinct phenotype. J Med Genet 50:838-847 (2013). 